\title{
In vitro Studies on Plant Regeneration in Elite Clones of Cocoa (Theobroma cacao L.)
}

\author{
S. Sreelekshmi* and B. Suma \\ Department of Horticulture, KAU P.O., Kerala Agricultural University, \\ Thrissur-680656, Kerala, India \\ *Corresponding author
}

\section{A B S T R A C T}

Keywords

In vitro, Cocoa, explants, Woody Plant Media, 2Isopentinyl Adenine, Indole-3Acetic Acid

Article Info

Accepted:

17 November 2019

Available Online:

10 December 2019
An experiment was carried out at Department of Plantation Crops and Spices, College of Horticulture, Vellanikkara with an objective to develop a protocol for in vitro regeneration and also to determine the variation in morphogenesis and regeneration among elite cocoa clones. The experiment was done in two factorial CRD using five cocoa varieties, CCRP 2, CCRP 6, CCRP 8, CCRP 15 and Scavina. Single nodded cuttings of 2-3 cm collected from the budded plants maintained in polyhouse were used as explants. The best surface sterilization of explants was achieved using Mancozeb 0.2 per cent, Streptocycline 0.1 per cent, Ethyl Alcohol 70 per cent and Mercuric Chloride 0.1 per cent. Axillary bud sprouting was induced in basal Woody Plant Media (WPM) fortified with 2-Isopentinyl Adenine (2ip) and Indole-3-Acetic Acid (IAA). The period of single shoot induction from leaf axils was lowest in variety CCRP 15 in media WPM+2ip 1ppm+IAA 0.02ppm. Among the varieties, highest multiple shoot induction percentage was recorded in variety Scavina.

\section{Introduction}

Cocoa (Theobroma cacao L.) is a beverage crop of huge economic significance. It is a key raw material for chocolate manufacturing. It is popularly known as 'Food of God' and considered divine from time immemorial. It is known to have originated from Central and Southern America. It belongs to family
Malvaceae and the genus Theobroma. Among the twenty two species of this genus, Theobroma cacao is the only commercially important one due to the value of its seeds. Seeds are commonly known as beans and are obtained from pods. The three cultivars of cocoa are Criollo, Forastero and Trinitario, which differ in its genetic origin, pod morphology, size, colour and flavour of beans 
(Wood and Lass, 1987). In addition to its flavour, cocoa is known to have notable health benefits. High levels of flavonoids have been linked to cardiovascular health benefits and reduces cholesterol level.

Cocoa is cultivated on land between 20 degrees north and south of equator. According to ICCO (International Cocoa Organization), the worldwide production of cocoa beans in 2015-16 is around 4 million metric tons and 70 per cent of world production is from African countries like Cote d 'Ivorie, Ghana, Nigeria and Cameroon.

The commercial cultivation of cocoa in India was started in 1980s and now it is mainly cultivated in the southern states like Kerala, Karnataka, Andhra Pradesh and Tamil Nadu. It is also considered as an ideal intercrop in coconut and arecanut based cropping systems. The present domestic availability is only about 30 per cent. Considering the market growth in the chocolate segment in India, which is about 15 per cent per annum, cocoa has a great potential to develop in coming years.

Cocoa is a perennial, cross pollinated and diploid plant. It is mainly propagated through seeds and are highly heterozygous due to open pollination. As a result, cocoa plants derived from seeds are highly variable in terms of their agronomic performance. However, the out crossing nature of the crop insist to develop seedlings only from specially designed polyclonal gardens, otherwise the quality of planting material will be drastically affected. The polyclonal gardens are available only with limited government institutions and the seedlings produced from here cannot meet the present demand.

Also, due to the non- availability of land and labour, there is limited scope for further expansion of poly clonal garden. The vegetative clonal propagation of superior cocoa genotypes has long been recognized as a potential means to increase cocoa production (Wood and Lass, 1987). However, progress in the development of improved methods for vegetative propagation of cocoa has been slow. In addition, there are a number of disadvantages associated with the propagation of cocoa plants via rooting, grafting or budding of plagiotropic cuttings including the intensive labour and associated costs and an undesirable bush like growth pattern which can occur.

In vitro propagation in cocoa can be considered as an alternative method of propagation that facilitate international exchange of planting material, speed up the diffusion of selected clones, keep the plant habit preferred and limit the dissemination of diseases which can be transmitted by conventional methods. It can also address the question of availability of bulk planting material.

Thus, clonal propagation of superior genotypes through in vitro methods was one of the identified thrust areas of cocoa biotechnology. Under this background, the present study was proposed with an objective to develop a protocol for in vitro regeneration among elite cocoa clones and to determine the variation in morphogenesis.

\section{Materials and Methods}

\section{Explant source and surface sterilization}

Single node segment from fan shoots of mother plants already protected with fungicides were used as explants. The cocoa varieties used in this study are CCRP 2, CCRP 6, CCRP 8, CCRP 15 and Scavina.

CCRP 2 - Variety evolved through single plant selection from local population. Trees are high yielding with smooth green pods. 
CCRP 6 - Variety evolved through single parent selection from exotic collection (IMC $10)$.

CCRP 8 - Hybrid between CCRP 1 and CCRP 7. High yielding and produces medium sized pods.

CCRP 15- Newly released hybrid from Kerala Agricultural University. Parentage - G VI 55 $\mathrm{X}$ Criollo.

Scavina - Exotic and a high tissue culture responding genotype.

The source plants were regularly sprayed with a systemic fungicide Carbendazim $(0.2 \%)$ and a contact fungicide Mancozeb $(0.3 \%)$ in an interval of three days to reduce fungal attack. Stems of approximately $10-15 \mathrm{~cm}$ were cut from the budded plants and were treated with Ethyl Alcohol 70 per cent for 3 minutes followed by $\mathrm{HgCl}_{2} 0.1$ per cent for 5 minutes. This treatment showed the highest survival percentage $(91.67 \%)$ of cultures with minimum microbial contamination (8.33\%). After each surface sterilization treatment, explants were thoroughly washed with distilled water.

\section{Standardization of culture establishment, multiple shoot induction and rooting}

The explants were cultured in media supplemented with growth regulators and were incubated in culture rooms at $28 \pm 2^{\circ} \mathrm{C}$ with a relative humidity of $80-90$ per cent under white fluorescent lamps provided for artificial illumination. As the experiment was done in two factorial CRD, the first factor media was tried at four different levels (Table 1) and the second factor was variety. Each treatment was done in 5 cocoa varieties like CCRP 2, CCRP 6, CCRP 8, CCRP 15 and Scavina. The number of replications were two. For multiple shoot induction, the surviving cultures were sub cultured at an interval of 2-3 weeks to medium containing silver nitrate. Addition of silver nitrate was suggested to overcome the problem of callus production at the cut ends of explants and also improve shoot regeneration. Each treatment of multiple shoot induction (Table 2) was done in 5 cocoa varieties like CCRP 2, CCRP 6, CCRP 8, CCRP 15 and Scavina.

The shoots obtained were subjected to rooting under in vitro condition using half strength MS medium after pulse treatment with IBA 1000-5000 ppm for 2-3 sec. Each treatment was done in 5 cocoa varieties like CCRP 2, CCRP 6, CCRP 8, CCRP 15 and Scavina.

\section{Results and Discussion}

\section{Culture establishment}

The basal media for culture establishment was WPM supplemented with different concentrations of 2ip and IAA. Bindu (1997) reported that the best basal medium for the culture establishment indicated by bud break, shoot elongation and leaf production in cocoa was the full strength WPM. This was also in conformity with the findings of McCown (2000) who used 2-ip in WPM in woody species like Azalea and Rhododendron for better culture establishment. Mallika et al., (1992) reported that in basal WPM, the cultures could be also maintained for a long time without chlorosis and leaf abscission. Karun and Bhavyashree (2011) reported that bud burst and sustained growth of shoots of cocoa under in vitro condition could be achieved when nodal segments were cultured in WPM containing additional supplements.

The period of shoot induction for five cocoa varieties in different culture establishment media is shown in Table 3. The period of shoot induction for all the five varieties was significantly influenced by the media, varieties 
and their interactions. Irrespective of the variety, it was recorded lowest in WPM + 2-ip $1 \mathrm{ppm}+$ IAA $0.02 \mathrm{ppm}$ (8.41). Irrespective of media used, the lowest period of shoot induction was noted in CCRP 2 (7.10) and this was statistically on par with variety Scavina (8.37). Interaction effect of media and varieties showed that, the period of shoot induction was lowest in variety CCRP 15 and the media WPM + 2-ip 1 ppm + IAA 0.02 ppm (6.33). Bindu (1997) had studied the number of days for bud break in cocoa and stated that the minimum number of days for bud break was 7.33 in WPM supplemented with 2-ip, adenine sulphate, silver nitrate, cycocel and phloroglucinol.

\section{Multiple shoot induction}

Production of multiple shoots in axillary bud culture was found to be ideal as it provides large number of plantlets from a single explant (Karun and Bhavyashree, 2011). In the present study, WPM with different concentration of 2ip and silver nitrate was used for multiple shoot induction. According to Mallika et al., (1992), callus formation can be encountered in any explant of cocoa when inoculated in medium without growth regulators. This is due to the presence of high levels of exogenous auxin and gibberellins in the plant.

Callusing at the base of explants leads to stunted growth and later, drying of shoots may occur. Addition of silver nitrate reduced the callus formation at the base of nodal stem explants of cocoa and this was in conformity with the result of Bindu (1997).The multiple shoot induction percentage in different cocoa varieties is depicted in Table 4. Shoot induction percentage varies significantly among media. Highest shoot induction percentage was recorded in WPM + 2-ip 4 ppm + IAA $0.08 \mathrm{ppm}+\mathrm{AgNO}_{3} 5 \mathrm{ppm}(91.67$ $\%)$ which was followed by WPM + 2-ip 3 $\mathrm{ppm}+\mathrm{IAA} 0.06 \mathrm{ppm}+\mathrm{AgNO}_{3} 5 \mathrm{ppm}(86.67$
\%). Among the different varieties, highest shoot induction percentage was recorded in Scavina (93.75 \%), followed by CCRP 2 $(85.42 \%)$.

There was significant variation in shoot induction percentage with respect to the different media and varieties. Shoot induction percentage varies from $66.67 \%$ to $100 \%$.

Interaction effect of multiple shoot induction media and variety showed cent per cent shoot induction in WPM + 2-ip 1 ppm + IAA 0.02 $\mathrm{ppm}+\mathrm{AgNO}_{3} 5 \mathrm{ppm}$ and $\mathrm{WPM}+2$-ip $2 \mathrm{ppm}$ + IAA $0.04 \mathrm{ppm}+\mathrm{AgNO}_{3} 5 \mathrm{ppm}$ for Scavina, $\mathrm{WPM}+2$-ip $3 \mathrm{ppm}+\mathrm{IAA} 0.06 \mathrm{ppm}+\mathrm{AgNO}_{3}$ $5 \mathrm{ppm}$ for CCRP 8 and WPM + 2-ip $4 \mathrm{ppm}+$ IAA $0.08 \mathrm{ppm}+\mathrm{AgNO}_{3} 5 \mathrm{ppm}$ for CCRP 2 .

\section{Rooting}

Shoot induction percentage and multiple shoot induction percentage were together high in cocoa but the number of shoots with minimum growth for inoculation in culture tubes for rooting was low. Thus, the rooting experiment was tried in limited number of cultures. In vitro shoots were kept for rooting in half strength MS medium after pulse treatment with IBA at different concentrations. Some of the cultures showed rooting after 1 month.

Among the media tried, $1 / 2 \mathrm{MS}+$ IBA 4000 ppm (pulse treatment for $2-3 \mathrm{sec}$ ) and $1 / 2 \mathrm{MS}+$ IBA $5000 \mathrm{ppm}$ (pulse treatment for 2-3 sec) were found to be congenial (Fig. 1). All the five varieties showed successful root induction in $1 / 2 \mathrm{MS}+$ IBA $5000 \mathrm{ppm}$ (pulse treatment for 2-3 sec). However, two varieties, CCRP 15 and Scavina, had successful root induction in $1 / 2 \mathrm{MS}+\mathrm{IBA} 4000 \mathrm{ppm}$ (pulse treatment for 2$3 \mathrm{sec}$ ). Hence in general, it can be concluded that among all the media tried for root induction, $1 / 2 \mathrm{MS}+$ IBA 5000 ppm (pulse treatment for 2-3 sec) proved to be superior. 
Table.1 Combination of growth regulators for culture establishment Basal medium: WPM

\begin{tabular}{|c|c|}
\hline Treatments & $\begin{array}{c}\text { Plant growth regulators } \\
\text { (ppm) }\end{array}$ \\
\hline $\mathbf{C E}_{\mathbf{1}}$ & 2-ip 1.00 + IAA 0.02 \\
\hline $\mathbf{C E}_{\mathbf{2}}$ & 2-ip 2.00 + IAA 0.04 \\
\hline $\mathbf{C E}_{\mathbf{3}}$ & 2-ip 3.00+ IAA 0.06 \\
\hline $\mathbf{C E}_{\mathbf{4}}$ & 2-ip 4.00+ IAA 0.08 \\
\hline
\end{tabular}

CE - Culture Establishment

Table.2 Combination of growth regulators for multiple shoot induction Basal medium: $\mathrm{WPM}+\mathrm{AgNO}_{3} 5 \mathrm{ppm}$

\begin{tabular}{|c|c|}
\hline Treatments & $\begin{array}{c}\text { Plant growth regulators } \\
\text { (ppm) }\end{array}$ \\
\hline $\mathbf{M S}_{\mathbf{1}}$ & 2-ip 1.00 + IAA 0.02 \\
\hline $\mathbf{M S}_{\mathbf{2}}$ & 2-ip 2.00 + IAA 0.04 \\
\hline $\mathbf{M S}_{\mathbf{3}}$ & 2-ip 3.00+ IAA 0.06 \\
\hline $\mathbf{M S}_{\mathbf{4}}$ & 2-ip 4.00+ IAA 0.08 \\
\hline
\end{tabular}

MS - Multiple Shoot

Table.3 Effect of culture establishment media, varieties and their interactions on period of shoot induction

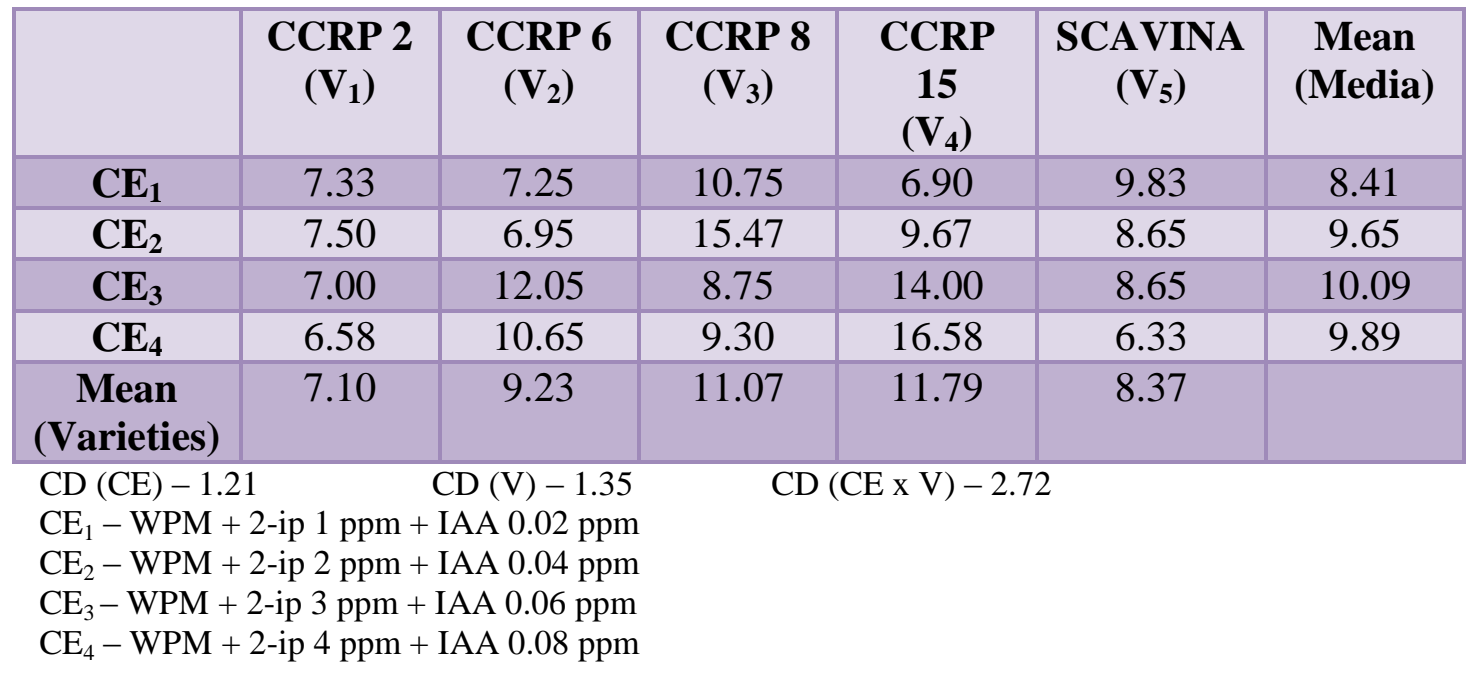


Table.4 Effect of multiple shoot induction media, varieties and their interactions on percentage shoot induction

\begin{tabular}{|c|c|c|c|c|c|c|}
\hline & $\begin{array}{c}\text { CCRP 2 } \\
\left(\mathbf{V}_{\mathbf{1}}\right)\end{array}$ & $\begin{array}{c}\text { CCRP 6 } \\
\left(\mathbf{V}_{\mathbf{2}}\right)\end{array}$ & $\begin{array}{c}\text { CCRP 8 } \\
\left(\mathbf{V}_{\mathbf{3}}\right)\end{array}$ & $\begin{array}{c}\text { CCRP 15 } \\
\left(\mathbf{V}_{\mathbf{4}}\right)\end{array}$ & $\begin{array}{c}\text { SCAVINA } \\
\left(\mathbf{V}_{\mathbf{5}}\right)\end{array}$ & $\begin{array}{c}\text { Mean } \\
(\text { Media) }\end{array}$ \\
\hline $\mathbf{M S}_{\mathbf{1}}$ & 9.62 & 9.19 & 7.14 & 7.14 & 10.05 & 8.63 \\
& $(91.67)$ & $(83.33)$ & $(50.00)$ & $(50.00)$ & $(100.00)$ & $(75.00)$ \\
\hline $\mathbf{M S}_{\mathbf{2}}$ & 8.23 & 8.23 & 9.18 & 8.23 & 10.05 & 8.79 \\
& $(66.67)$ & $(66.67)$ & $(83.33)$ & $(66.67)$ & $(100.00)$ & $(76.67)$ \\
\hline $\mathbf{M S}_{\mathbf{3}}$ & 9.18 & 9.18 & 9.62 & 9.18 & 9.62 & 9.36 \\
& $(83.33)$ & $(83.33)$ & $(91.67)$ & $(83.33)$ & $(91.67)$ & $(86.67)$ \\
\hline $\mathbf{M S}_{\mathbf{4}}$ & 10.05 & 9.62 & 9.62 & 9.62 & 9.18 & 9.68 \\
& $(100.00)$ & $(91.67)$ & $(91.67)$ & $(91.67)$ & $(83.33)$ & $(91.67)$ \\
\hline Mean & 9.27 & 9.05 & 8.89 & 8.54 & 9.74 & \\
$($ Varieties & $(85.42)$ & $(81.25)$ & $(79.17)$ & $(72.92)$ & $(93.75)$ & \\
\hline
\end{tabular}

$\sqrt{x}+0.5$ transformed values, original values are given in parenthesis
$\mathrm{CD}(\mathrm{MS})-0.31$
$\mathrm{CD}(\mathrm{V})-0.35$
$\mathrm{CD}(\mathrm{MS} \times \mathrm{V})-0.70$

$\mathrm{MS}_{1}-\mathrm{WPM}+2$-ip $1 \mathrm{ppm}+\mathrm{IAA} 0.02 \mathrm{ppm}+\mathrm{AgNO}_{3} 5 \mathrm{ppm}$

$\mathrm{MS}_{2}-\mathrm{WPM}+2$-ip $2 \mathrm{ppm}+\mathrm{IAA} 0.04 \mathrm{ppm}+\mathrm{AgNO}_{3} 5 \mathrm{ppm}$

$\mathrm{MS}_{3}-\mathrm{WPM}+2$-ip $3 \mathrm{ppm}+\mathrm{IAA} 0.06 \mathrm{ppm}+\mathrm{AgNO}_{3} 5 \mathrm{ppm}$

$\mathrm{MS}_{4}-\mathrm{WPM}+2$-ip $4 \mathrm{ppm}+\mathrm{IAA} 0.08 \mathrm{ppm}+\mathrm{AgNO}_{3} 5 \mathrm{ppm}$

Fig.1 Percentage of root induction in different cocoa varieties in rooting media

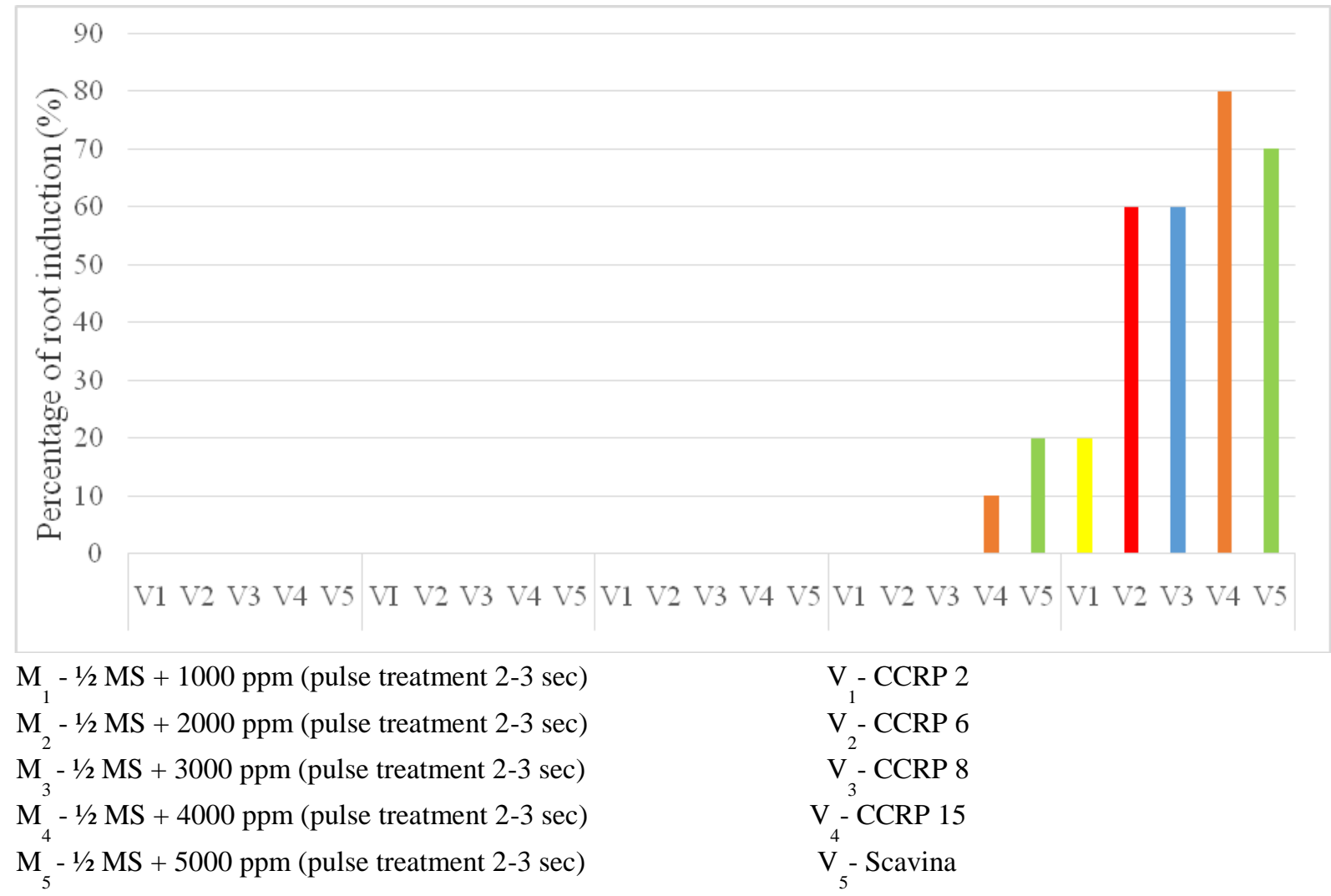


Nair et al., (1993) reported that cocoa shoots shows low root induction percentage under in vitro condition (20-30 \%). This was also supported by the findings of Bindu (1997).

In the present study, the basal half MS medium with pulse treatment of IBA 5000 ppm showed maximum rooting in cultures. Bindu (1997) highlighted that pretreatment of in vitro cocoa shoots with IBA $5000 \mathrm{mg}^{-1}$ for $3 \mathrm{sec}$ followed by culturing in half strength MS media was ideal for root induction. Studies of Komalavalli and Rao (2000) and Shekhawat et al., (2015) also revealed that basal half MS medium supplemented with growth regulators was best for root induction under in vitro condition.

Karun and Bhavyashree (2011) reported that rooting of in vitro shoots derived from axillary buds could be accomplished by pulse treatment with IBA at various concentrations. The healthy roots were produced when auxin treatment was given to the shoots followed by transferring to an auxin free medium with activated charcoal.

In conclusion, in the present study, period of shoot induction for all the five cocoa varieties was significantly influenced by media, varieties and their interactions. Irrespective of the variety, it was recorded lowest in WPM + 2-ip $1 \mathrm{ppm}+$ IAA 0.02 ppm (8.41). Irrespective of media used, the lowest period of shoot induction was noted in CCRP 2 (7.10) and this was statistically on par with varieties Scavina (8.37). Interaction effect of media and varieties showed that, the period of shoot induction was lowest (6.33) in variety CCRP 15 when media WPM + 2-ip 1 ppm + IAA $0.02 \mathrm{ppm}$ was used. Shoot induction percentage vary significantly among media, varieties and their interactions. Interaction effect of multiple shoot induction media and variety showed cent per cent shoot induction in $\mathrm{WPM}+2$-ip $1 \mathrm{ppm}+$ IAA $0.02 \mathrm{ppm}+$
$\mathrm{AgNO}_{3} 5 \mathrm{ppm}$ and WPM + 2-ip $2 \mathrm{ppm}+\mathrm{IAA}$ $0.04 \mathrm{ppm}+\mathrm{AgNO}_{3} 5 \mathrm{ppm}$ for Scavina, WPM +2 -ip $3 \mathrm{ppm}+\mathrm{IAA} 0.06 \mathrm{ppm}+\mathrm{AgNO}_{3} 5$ ppm for CCRP 8 and WPM + 2-ip 4 ppm + IAA $0.08 \mathrm{ppm}+\mathrm{AgNO}_{3} 5 \mathrm{ppm}$ for CCRP 2 . Rooting percentage was generally low under in vitro condition. Among the media tried, $1 / 2$ MS + IBA 4000 ppm (pulse treatment for 2-3 sec) and $1 / 2 \mathrm{MS}+$ IBA 5000 ppm (pulse treatment for 2-3 sec) were found to be ideal and two varieties, CCRP 15 and Scavina, had successful root induction in $1 / 2 \mathrm{MS}+$ IBA 4000 ppm (pulse treatment for 2-3 sec). Hence in general, it can be concluded that, among all the media tried for root induction, $1 / 2 \mathrm{MS}+$ IBA $5000 \mathrm{ppm}$ (pulse treatment for $2-3 \mathrm{sec}$ ) proved to be superior.

\section{Acknowledgement}

The authors wish to express sincere thanks to Kerala Agricultural University for financial assistance. Express their gratitude to Dr. Nalini P. V., Dr. Minimol J. S. and Dr. Lissamma Joseph, College of Horticulture for their valuable suggestions.

\section{References}

Bindu, M.R. 1997. Standardisation of in vitro techniques for rooting, hardening and micrografting in cocoa (Theobroma cacao L.). Ph. D. (Ag) thesis, Kerala Agricultural University, Thrissur, $135 \mathrm{p}$.

Karun, A and Bhavyashree, U. 2011. In vitro multiplication of cocoa. In: Apshara, S. E., Jaganathan, D. and Balasimha, D. (ed.), Proceedings of seminar on strategies for enhancing productivity of cocoa. 28-29 Jan. 2011. CPCRI, Regional station, Vittal, Karnataka. 206p.

Komalavalli, N. and Rao, M. V. 2000. In vitro micropropagation of Gymnema sylvestre-A multipurpose medicinal 
plant. Plant Cell, Tissue and Organ Cult. 61(2): 97.

Mallika, V. K., Sankar, A. M., Sindhu, K., Rekha, C., Vijayakumar, N. K. and Nair, R.V. 1992. Plantlet regeneration in vitro from nodal segments of cocoa (Theobroma cacao L.) andfield planting. J. Plantn. Crops. 20: 114122.
McCown, B. H. 2000. Woody shrubs and trees. Plant Tissue Cult. Tech. and Exp. pp. 128-133.

Shekhawat, M. S., Kannan, N., Manokari, M., and Ravindran, C. P. 2015. Enhanced micropropagation protocol of Morinda citrifolia L. through nodal explants. $J$. Appl. Res. Med. and Aromat. Plants. 2(4): 174-181.

\section{How to cite this article:}

Sreelekshmi, S. and Suma, B. 2019. In vitro Studies on Plant Regeneration in Elite Clones of Cocoa (Theobroma cacao L.). Int.J.Curr.Microbiol.App.Sci. 8(12): 2368-2375. doi: https://doi.org/10.20546/ijcmas.2019.812.279 